\title{
The Biopsychosocial Actor in the Contexts of Health and Human Services Informatics
}

\author{
Jaakko HAKULA ${ }^{\mathrm{a}, 1}$ \\ ${ }^{a}$ Department of Health and Social Management, University of Eastern Finland, \\ Finland
}

\begin{abstract}
The paradigm for health and human services informatics (HHSI) was developed by Finnish researchers. The four entities of the HHSI paradigm and their interrelations form the basics for informatics research and education in the University of Eastern Finland. The focus of the essay is on the entities of actors and action related to different conceptions of agency. The entities of data and technology are the backbones of digitalization. The further aim of the study is to modernize the Holistic Concept of Man (HCM) metaphor to take the form of the biopsychosocial (BPS) actor. The HCM metaphor with its Husserlian-Heideggerian backgrounds is renovated towards a more realistic model of an individual actor or decision-maker described by the BSP model. As the BSP actor is embedded in the contexts of the HHSI paradigm, the notion of the BPS-D actor or decision-maker emerges. The BPS-D actor is a hybrid agent, who has cognitive, emotional, informational, and action-oriented connections to other possible agencies and artificial systems in the digitalized encounter. The very context of future research is the HHSI neo-paradigm.
\end{abstract}

Keywords. HHSI paradigm, agency, HCM metaphor, BPS model, BPS-D actor

\section{Introduction}

The term informatics encompasses people, information, and technology. The paradigm for health and human services informatics (HHSI) is related to health and biomedical informatics. The HHSI paradigm was developed along the utilization of information technology in the health and social sciences in the University of Eastern Finland, where it is widely used in research and education. It is composed of four main entities - actors, action, data, and technology [1]. Health and human services informatics confronts many practical challenges in the integration of multifaceted ontologies in and between healthcare and social services [2]. Especially the role of artificial intelligence (AI) in future health technology assessment (HTA) is becoming increasingly important [3].

Real-world research practices define the order of preferences between the main entities of the HHSI paradigm. Depending on the emphasis of argumentation between the paradigmatic entities and/or the links, the contents of research and education vary. Research on information management in service processes is determined by the combination of data, as the value chain of information, and action. Research on action and technology produces evaluation and development research on information and communication technology. The combination of technology and actors generates

${ }^{1}$ Corresponding Author, Jaakko Hakula, Department of Health and Social Management, University of Eastern Finland, 70211 Kuopio, Finland; E-mail: jaakko.hakula@dnainternet.net. 
research on knowledge management. Scientific and developmental work on the body of knowledge originate in the interrelationship between actors and data as information [1].

In 1977 Engel presented the biopsychosocial (BPS) model to broaden restrictions of the dominating biomedical model [4]. The BPS model inherits its holistic, multilevel ontology, and epistemological and methodological essence from general systems theory [5]. The abstraction of the nested organization of micro, meso, and macro levels of natural systems is the basis for scientific research of the BPS model. The holistic structure of the BPS model with functionalistic properties is of use also in making every day encounters of cure and care more humane [5-6].

Agency as human intentional action, and as possible, non-human artificial property, are not strictly separated in informatics research. Whether artificial technical systems fulfill the definition of agency is debatable. Human actors (as agents) acting in contexts of digitalized information systems communicate and cooperate individually sharing the agentic environment with another individual actor, or collectively in larger coalitions [7].

The three-partite Holistic Concept of Man (HCM) represents a philosophic metaphor of agency, based on Husserlian-Heideggerian schools of thought. The HCM metaphor originates in works of the late Lauri Rauhala, a Finnish philosopher, and of Pekka Pihlanto, a professor emeritus of management accounting. The HCM metaphor consists of consciousness, corporeality, and situationality. It emphasizes the role of individual actors in everyday contexts of life. It has been applied mainly by Finnish researchers, e.g. in areas of management, information sciences, and rehabilitation [8]. The aim of the study is to sketch a novel model of agency in the context of the HHSI paradigm.

\section{Materials and methods}

Materials and methods are closely connected to each other. The HHSI paradigm with its entities and their functions, the HCM metaphor, and the BPS model are the materials of the study that are conceptually analyzed and resynthesized. The "end-product" is but an instantiation of metamorphosis towards something new to be applied in future studies, e.g. in areas of management, information sciences, and rehabilitation.

The methods could be broadly called philosophical as the conceptions in relation to the language and drawings used reflect various historical schools of scientific thinking. Informatics, management and technology in healthcare are an interdisciplinary endeavour. Materials and methods are supported by general systemic principles.

\section{Results}

Figure 1 depicts the BPS actor reformulated from the HCM metaphor, which stands for the initial actor in the digitalized context steered by the HHSI paradigm. The HHSI paradigm as a whole is presented divergent from the original pictorial expression but the ontologies and interrelations of the paradigmatic entities are considered to remain as earlier defined [1]. Human agency as the BPS actor is positioned in the center of responsible action. The BSP actor inherits the concepts of mind and body, and activities towards objects from the HCM metaphor. However, the main tenets of the HCM metaphor - consciousness, corporeality and situationality - are replaced by those of psychological, biological and social determinants of the BPS model [4-6]. 
The HHSI neo-paradigm in Figure 1 reflects the three basic onto-epistemological and ethical properties of holistic conceptions of health and disease from an individual perspective. Cognitive and emotional factors intermingle with general and special knowledge and information [9]. Motor action is closely linked to cognition and emotion [10] (omitted in the contexts of the HCM metaphor). The BPS model can be expanded to digitalized encounters: the biopsychosocial-digital (BPS-D) actor as a hybrid agent is imagined to have human, intentional properties, and possible artificial elements.

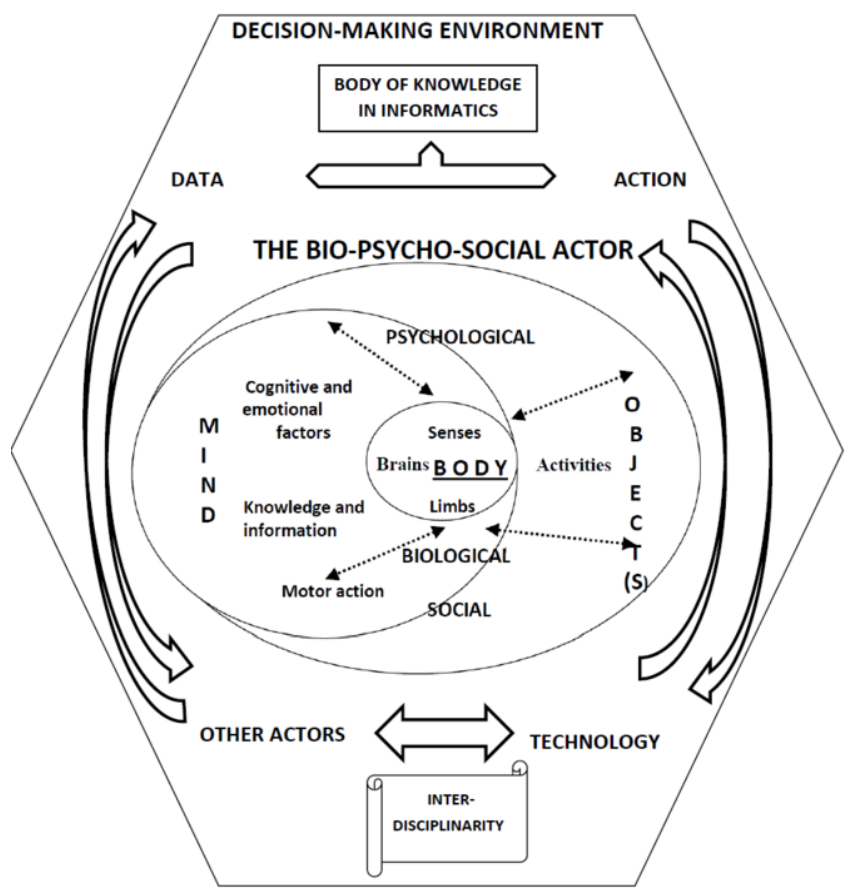

Figure 1. The BPS-actor and the HHSI neo-paradigmatic expansion

The BPS actor may represent a human expert or a layman but not an artificial system. Artificial systems are embedded in all of the entities of the HHSI (neo)-paradigm, with their interconnections, although they might be called artificial agents metaphorically. The BPS-D actor evolves in the systems of the neo-paradigmatic environment.

\section{Discussion}

The notion of the BPS-D actor, with its hybridity, amplifies the HHSI neo-paradigm towards more individually inclined research to be made both in information management of healthcare and social services, patient care, and rehabilitation. The problem of systemic, holistic models is their complexity: everything has an impact on everything. Quality and/or quantity - validity and repeatability - where is the relevance?

The HHSI (neo)-paradigm actualizes as a conglomerate of multiple paradigms that support transdisciplinary research and education - and indirectly everyday work 
activities in health and human services informatics. Anomalies of the HHSI paradigm have been scarcely studied, which might justify a deeper thought on the Kuhnian symbolism. One relevant topic in this respect could be different scopes of agency.

\section{References}

[1] Kuusisto-Niemi S, Saranto K, Rissanen S. Informatics in social science: research, developments, and outcomes from the Finnish perspectives. In: Tavana M, Ghapanchi AH, Talaei-Khoei A, editors. Healthcare informatics and analytics: emerging issues and trends [Internet]. Hershey (PA): IGI Global, 2015 [cited 2021 Jan 04]. Chapter 2. Available from: https://www.igi-global.com/chapter/informaticsin-social-services/115105 DOI: 10.4018/978-1-4666-6316-9.ch002.

[2] Fichtenberg C, Delva J, Minyard K, Gottlieb LM. Health and human services integration: generating sustained health and equity improvement. Health Affairs [Internet]. 2020 Apr 20 [cited 2021 Jan 12];39(4):567-573. Available from: https://www.healthaffairs.org/doi/10.1377/hlthaff.2019.01594 DOI: $10.1377 /$ hlthaff.2019.01594.

[3] Alami H, Lehoux P, Auclair Y, de Guise M, Gagnon MP, Shaw J, Roy D, Fleet R, Ahmed MA, Fortin JP. Artificial intelligence and health technology assessment: anticipating a new level of complexity. Journal of medical Internet research. 2020;22(7):e17707.

[4] Bolton D. The biopsychosocial model and the new medical humanism. Archives de Philosophie [Internet].2020 Oct 28 [cited 2021 Sep 01];83(4):13-40. Available from: https://www.cairnint.info/article.php?ID_ARTICLE=E_APHI_834_0013 DOI:10.3917/aphi.834.0013.

[5] Karunamuni N, Imayama I, Goonetilleke D. Pathways to well-being: Untangling the causal relationships among biopsychosocial variables. Social Science \& Medicine [Internet]. 2020 Feb 10 [cited 2021 Sep 01];12 p. Available from: https://www.sciencedirect.com/science/article/abs/pii/S0277953620300654?via\%3Dihub DOI:10.1016/j.socscimed.2020.112846.

[6] Ahmadvand A, Gatchel R, Brownstein J, Nissen L. The Biopsychosocial-Digital Approach to Health and Disease: Call for a Paradigm Expansion. J Med Internet Res [Internet]. 2018 May [cited 2021 Aug 20];20(5):e189. Available from: https:/www.jmir.org/2018/5/e189/ DOI: 10.2196/jmir.9732.

[7] Schlosser M. Agency. [Internet]. The Stanford Encyclopedia of Philosophy (Winter 2019 Edition). Edward N. Zalta, editor. Stanford (CA): Stanford University, Center for Study of Language and Information, the Metaphysics Research Lab; 2019 Oct 28 [cited 2021 Aug 30]. Available from: https://stanford.library.sydney.edu.au/archives/win2019/entries/agency/.

[8] Markopoulos E, Vanharanta H.Delphic Maxims Based Applied Philosophy for Business and Governance Management. In: Kantola J, Barath T, Nazir S, Andre T, editors. Advances in human factors, business management, training and education. Advances in Intelligent Systems and Computing, vol 498 trends [Internet]. Cham:Springer;2017 [cited 2021 Aug 28]. Available from: https://link.springer.com/chapter/10.1007\%2F978-3-319-42070-7_4 DOI:10.1007/978-3-31942070-7_4.

[9] Dionne SD, Gooty J, Yammarino FJ, Sayama H. Decision making in crisis: A multilevel model of the interplay between cognitions and emotions. Organizational Psychology Review [Internet]. 2018 Oct 28 [cited $2021 \quad$ Sep 01$] ; 8(2-3): 95-124 . \quad$ Available https://journals.sagepub.com/doi/10.1177/2041386618756063 DOI: 10.1177/2041386618756063.

[10] Glenberg AM, Witt JK, Metcalfe J. From the Revolution to Embodiment: 25 Years of Cognitive Psychology. Perspect Psychol Sci [Internet]. 2013 Sep; [cited 2021 Sep 08];8(5):573-85. Available from: https://pubmed.ncbi.nlm.nih.gov/26173215/ DOI:10.1177/1745691613498098. 